\title{
AVASCULAR NECROSIS OF THE TALUS TREATED BY CORE DECOMPRESSION
}

\author{
MICHAEL A. MONT, LEW C. SCHON, MARC W. HUNGERFORD, DAVID \\ S. HUNGERFORD
}

From Johns Hopkins University, Baltimore, USA

W

Je reviewed 11 patients (17 ankles) who had had core decompression for symptomatic avascular necrosis of the talus before collapse. The Mazur grading system was used to assess function preoperatively and at final follow-up, and radiographs were graded according to the Ficat and Arlet (1980) classification modified for the ankle.

At a mean follow-up of seven years ( 2 to 14) 14 ankles $(82 \%)$ had an excellent or good outcome (Mazur scores $>80$ points; pain scores $>40$ points $(41$ to 50)). The other three ankles required tibiotalar fusion at a mean of 13 months (5 to 20) after core decompression.

We conclude that core decompression is a viable method of treatment for symptomatic avascular necrosis of the talus before collapse.

J Bone Joint Surg [Br] 1996;78-B:827-30.

Received 15 December 1995; Accepted after revision 16 May 1996

One of the well-recognised complications of severe ankle injury is avascular necrosis of the talus (Blair 1943; Hallock 1945; Dennis and Tullos 1980). It has also been reported in association with alcoholism (Harris and Silver 1973), corticosteroid use (Dall and MacNab 1970; Harris and Silver 1973; Cruess 1981; Langevitz et al 1990; Adleberg and Smith 1991), hyperlipidaemia (Harrington et al 1971), hyperuricaemia (Miskew and Goldflies 1980), occlusive vascular disease (Jones 1993), systemic lupus erythematosus (Baron, Paltiel and Lauder 1984; Adleberg and Smith 1991) and sickle-cell disease (Jones 1993). Occasionally, there are adjacent lesions in the tibial plafond

M. A. Mont, MD, Associate Professor

M. W. Hungerford, MD, Resident Orthopaedic Surgeon

D. S. Hungerford, MD, Professor

Johns Hopkins University School of Medicine, Department of Orthopaedic Surgery, Division of Arthritis Surgery, Good Samaritan Professional Building, 5601 Loch Raven Boulevard, Baltimore, Maryland 21239, USA.

L. C. Schon, MD, Attending Surgeon

Department of Orthopaedics, Union Memorial Hospital, Baltimore, Maryland 21239, USA.

Correspondence should be sent to Dr M. A. Mont.

(C)1996 British Editorial Society of Bone and Joint Surgery 0301-620X/96/51274\$2.00
(Jones 1993). The progression of avascular necrosis of the talus is similar to that of lesions in the femoral head (Jones 1993; Mont and Hungerford 1995). Our report is concerned with non-traumatic talar lesions which involve the dome and spare the talocalcaneal and talonavicular surfaces.

Operative treatment includes tibiotalar fusion and talectomy with tibiocalcaneal fusion (Barr and Record 1953; Morris, Hand and Dunn 1971; Mazur, Schwartz and Simon 1979; Dennis and Tullos 1980; Ahlberg and Henricson 1981; Sowa and Krackow 1989; Holt et al 1991; Kirkpatrick, Goldner and Goldner 1991; Mann et al 1991; Scranton 1991; Urquhart et al 1996). Core decompression has been reported as a treatment option for osteonecrosis of the hip (Ficat and Arlet 1980; Zizic and Hungerford 1985; Mont and Hungerford 1995) knee (Mont, Tomek and Hungerford 1997) and shoulder (Mont et al 1993) but has not been described for the ankle. Our aim is to report our experience of this method of treatment for non-traumatic avascular necrosis of the talus before collapse has occurred.

\section{PATIENTS AND METHODS}

Between October 1979 and September 1992, we performed core decompression in 11 patients (17 ankles) for avascular necrosis of the talus. There were ten women and one man with a mean age of 47 years (24 to 64). The mean followup was seven years (2 to 14) and no patient was lost to follow-up.

Seven patients (11 ankles) had systemic lupus erythematosus and were receiving systemic corticosteroids (>20 mg per day of prednisone for over one year). Two patients (three ankles) had chronic corticosteroid use associated with asthma in one and renal disease in the other. In two patients (three ankles), no identifiable associated cause for avascular necrosis had been found, but they may have had an alcohol consumption of about $400 \mathrm{ml}$ per week (Hirota et al 1993).

The diagnosis had been made by clinical and radiological evaluation with confirmation by biopsy in all cases. MRI had also confirmed the diagnosis in 12 patients and had been used to localise and delineate the extent of the lesion. All patients had either radiological stage I or stage II avascular necrosis according to Ficat and Arlet (1980) modified for the ankle (Table I), and all had severe ankle pain on weight-bearing, with a variable degree of pain at 


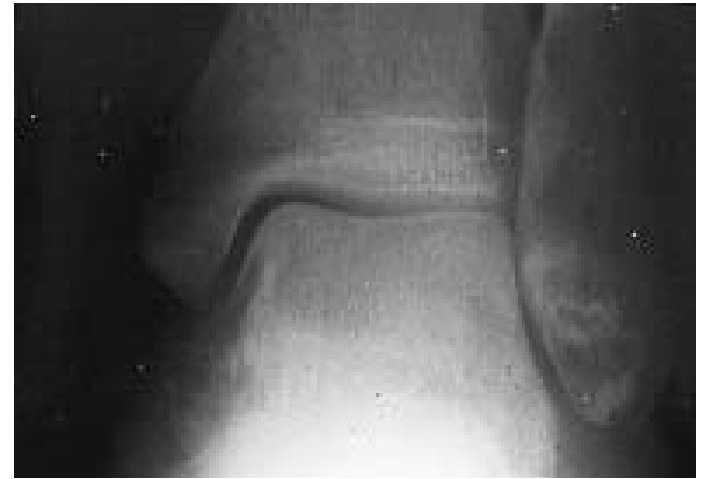

Fig. 1a

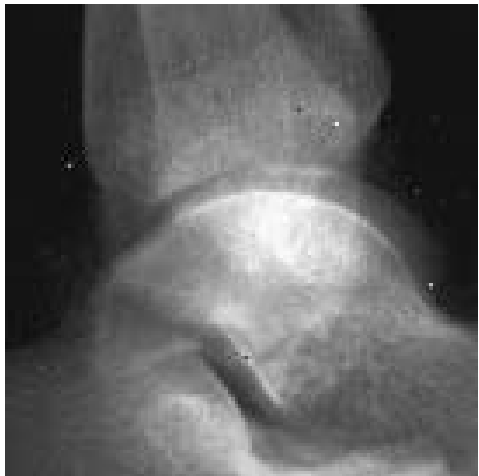

Fig. 1b

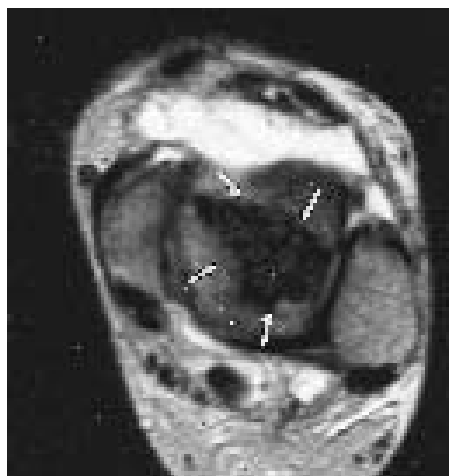

Fig. 1c

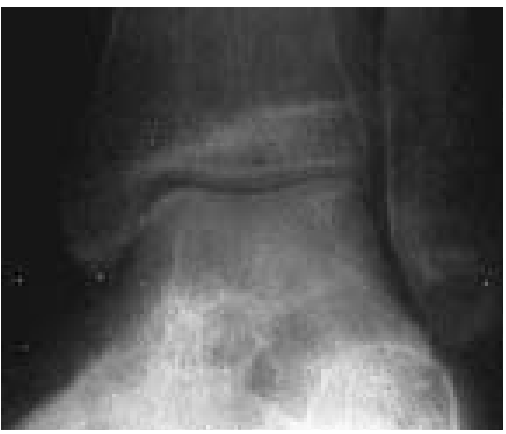

Fig. 1d

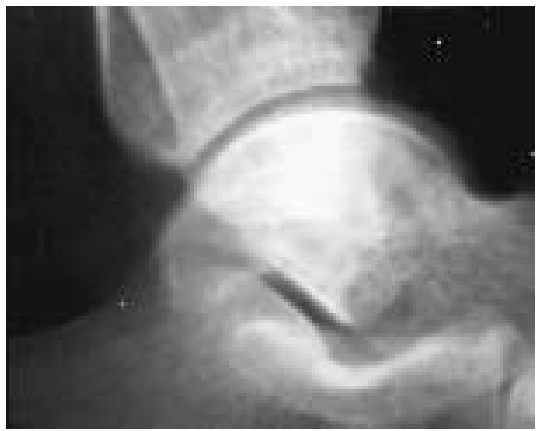

Fig. 1e
A 27-year-old woman with stage-I avascular necrosis of the talus. Figures $1 \mathrm{a}$ and $1 \mathrm{~b}-$ Anteroposterior and lateral radiographs before surgery. The lesion is not visible. Figure 1c - Coronal MRI. The large size of the lesion is apparent (arrows). Figures 1d and 1e - Anteroposterior and lateral radiographs seven years later.
Table I. Staging of avascular necrosis according to Ficat and Arlet (1950) modified for the ankle

\begin{tabular}{ll}
\hline Stage & Radiological appearance \\
\hline I & Normal \\
II & $\begin{array}{l}\text { Cystic and/or osteosclerotic lesions, normal contour of talus, } \\
\text { no subchondral fracture }\end{array}$ \\
III & Crescent sign or subchondral collapse \\
IV & $\begin{array}{l}\text { Joint-space narrowing, secondary distal tibial changes (cysts, } \\
\text { marginal osteophytes and destruction of the cartilage) }\end{array}$ \\
\hline
\end{tabular}

rest. None had responded to a minimum of three months of non-operative treatment which included the use of anklefoot orthoses and analgesics.

Operative technique. This was performed on an outpatient basis by three of the authors (MAM, LCS, DSH). A standard anterolateral or anteromedial approach to the talar dome was used in all but three patients. In three patients, ankle arthroscopy allowed visualisation of the talar body. In all ankles the $4 \mathrm{~mm}$ trocar was inserted through an anteromedial or anterolateral portal, and one hole was made at the distal aspect of the talus through one of these entry sites. Fluoroscopy was used for biplane localisation of the biopsy cannula which was directed in one pass medially or one pass laterally or both depending on the extent of the lesion, based on MRI evaluation. Postoperatively, partial weightbearing was allowed for six weeks and then full weightbearing as tolerated.

Clinical evaluation. This used the Mazur ankle grading system (Mazur et al 1979). The 100-point scale is based on pain, range of movement and activity level. An excellent result scored 90 to 100 points; a good result 80 to 89; a fair result 70 to 79 ; and a poor result scored less than 70 . The final evaluation was by examination $(n=14)$ or by telephone and a report from the patient's present orthopaedic surgeon $(n=3)$.

\section{RESULTS}

At final follow-up 14 ankles had excellent (11) and good (3) results. The mean preoperative Mazur ankle score was 35 points ( 12 to 40 ); postoperatively it was 92 points (84 to 96). The mean pain score was 46 points (41 to 50) (Figs 1 and 2). The remaining three ankles had a poor clinical outcome necessitating tibiotalar fusion at a mean of 13 months (5 to 20) after the core decompression. All united with an excellent clinical outcome.

Radiologically, only five ankles progressed to Ficat stage III or stage IV (collapse) which included the three which required fusion and two others which had some degree of collapse (stage III) but were asymptomatic (Mazur score >90). There were no complications. All patients resumed full weight-bearing after six weeks.

\section{DISCUSSION}

Methods of treatment for symptomatic avascular necrosis of the talus are limited. If conservative treatment fails, the 


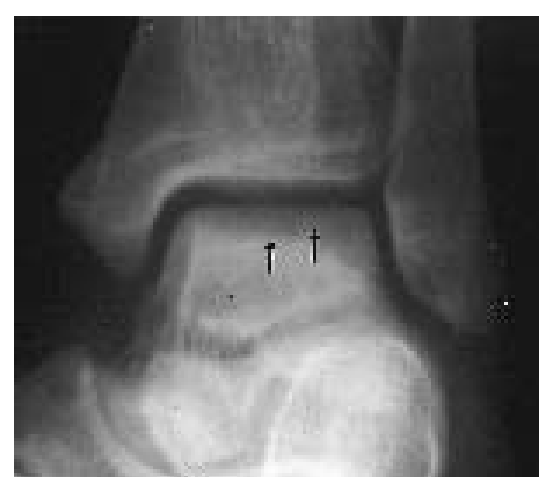

Fig. 2a

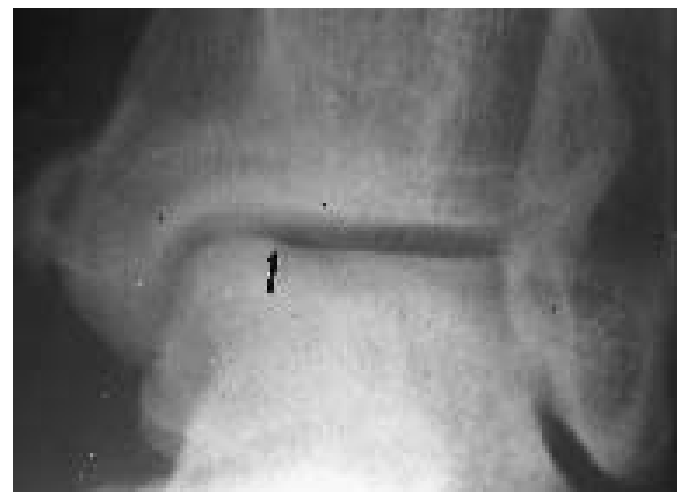

Fig. 2d

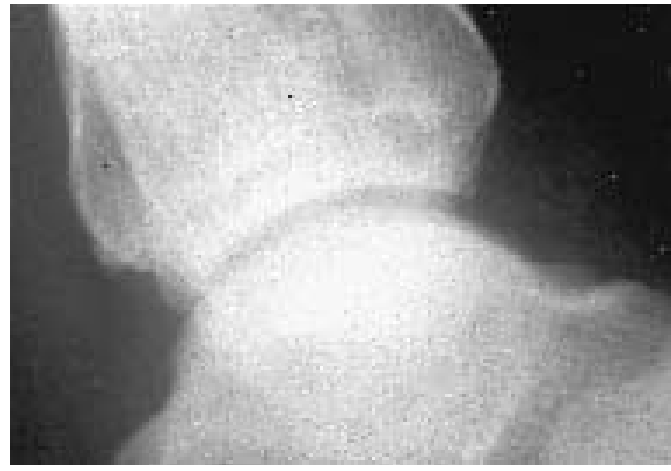

Fig. $2 b$

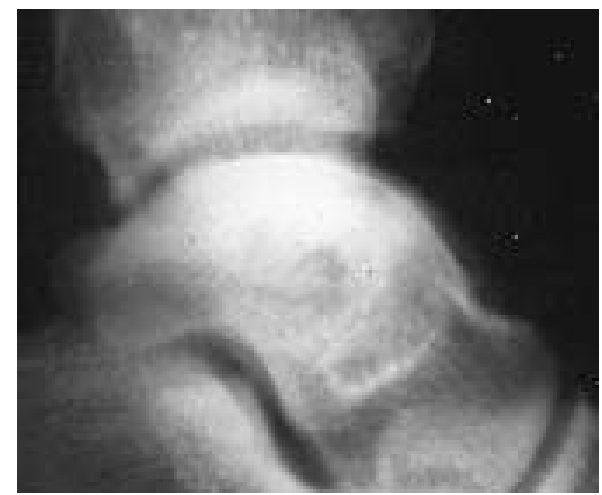

Fig. 2e

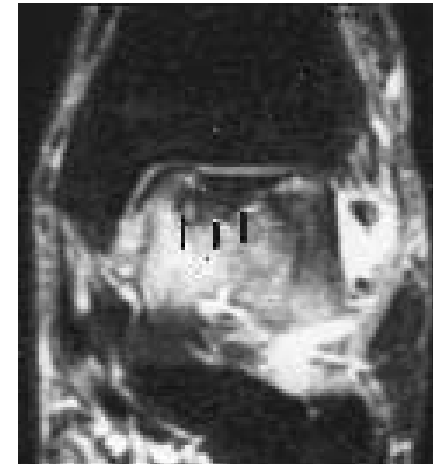

Fig. 2c

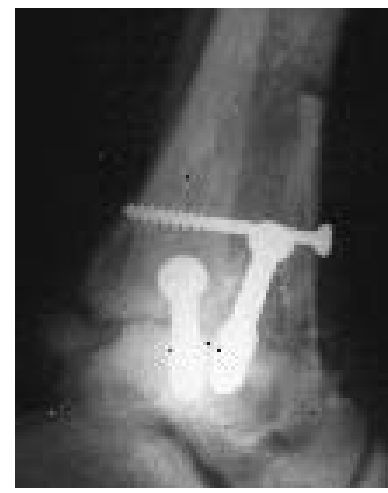

Fig. $2 \mathrm{f}$

A 40-year-old woman with stage-II avascular necrosis of the talus. Figures $2 \mathrm{a}$ and $2 \mathrm{~b}$ - Anteroposterior and lateral radiographs before surgery (arrow denotes the lesion on the AP film). Figure $2 \mathrm{c}-\mathrm{MRI}$ of the talus (arrows pointing to the lesion). Figures $2 \mathrm{~d}$ and $2 \mathrm{e}-\mathrm{Anteroposterior}$ and lateral radiographs one year later with collapse noted on the AP film (black arrow). Figure $2 \mathrm{f}$ - Lateral radiograph of ankle after tibiotalar fusion.

surgeon is left with only a few options which include various arthrodeses and core decompression.

Hindfoot fusions in these patients are technically challenging, and operating times are longer than in patients with rheumatoid or osteoarthritis mainly because of the difficulty in achieving well-vascularised bony surfaces for fusion. In addition, these patients require a much longer time to fusion, more than seven months compared with the three or four months reported for patients without avascular necrosis (Blair 1943; Kirkpatrick et al 1991; Urquhart et al 1996). In one study (Kirkpatrick et al 1991), two of ten cases of nonunion of tibiotalar arthrodesis were in patients with talar avascular necrosis and Holt et al (1991) noted only a $38 \%$ success rate for fusion in such patients. In a recent study (Frey et al 1994), nonunion occurred after attempted fusion in eight out of nine patients with talar avascular necrosis. Urquhart et al (1996) found that hindfoot fusion in patients with talar avascular necrosis was technically demanding and required a longer period of immobilisation when compared with other patients.

Core decompression is a satisfactory solution for symptomatic lesions. Before collapse has occurred it has minimal morbidity and can be performed as an outpatient procedure. This treatment seems to be a realistic option in patients who have not progressed to end-stage tibiotalar arthritis.

Our study has its limitations in that it was not prospective and the numbers are small. Unfortunately, the rarity of the condition (about 30 cases over a 15-year period) precludes a randomised, controlled study from one centre concerning various treatment options. There are no studies on the natural history of the disease. We believe that a multicentre, randomised study is necessary to compare core decompression with other methods such as bone grafting or electrical stimulation.

No benefits in any form have been received or will be received from a commercial party related directly or indirectly to the subject of this article.

\section{REFERENCES}

Adleberg JS, Smith GH. Corticosteroid-induced avascular necrosis of the talus. J Foot Surg 1991;30:66-9.

Ahlberg A, Henricson AS. Late results of ankle fusion. Acta Orthop Scand 1981;52:103-5.

Baron M, Paltiel H, Lander P. Aseptic necrosis of the talus and calcaneal insufficiency fractures in a patient with pancreatitis, subcutaneous fat necrosis and arthritis. Arthritis Rheum 1984;27:1309-13.

Barr JS, Record EE. Arthrodesis of the ankle joint: indications, operative technic and clinical experience. $N$ Engl J Med 1953;248:53-6.

Blair HC. Comminuted fractures and fracture dislocations of the body of astralagus: operative treatment. Am J Surg 1943;59:37-43. 
Cruess RL. Steroid-induced osteonecrosis: a review. Can J Surg 1981;24:567-71.

Dall D, MacNab I. Spontaneous avascular necrosis of the talus: a report of two cases. S Afr Med J 1970;44:193-6.

Dennis MD, Tullos HS. Blair tibiotalar arthrodesis for injuries to the talus. J Bone Joint Surg [Am] 1980;62-A:103-7.

Ficat RP, Arlet J. Ischemia and necrosis of bone. Baltimore, etc: Williams and Wilkins, 1980:171-82.

Frey C, Halikus NM, Vu-Rose T, Ebramzadeh E. A review of ankle arthrodesis: predisposing factors to nonunion. Foot Ankle Int 1994; 15:581-4.

Hallock H. Arthrodesis of the ankle joint for old painful fractures. $J$ Bone Joint Surg [Am] 1945;27-A:49-58.

Harrington KD, Murray WR, Kountz SL, Belzer FO. Avascular necrosis of bone after renal transplantation. J Bone Joint Surg [Am] 1971;53-A:203-15.

Harris RD, Silver RA. Atraumatic aseptic necrosis of the talus. Radiology 1973;106:81-3.

Hirota Y, Hirohata T, Fukuda K, et al. Association of alcohol intake, cigarette smoking, and occupational status with the risk of idiopathic osteonecrosis of the femoral head. Am J Epidemiol 1993; 137:530-8.

Holt ES, Hansen ST, Mayo KA, Sangeorzan BJ. Ankle arthrodesis using internal screw fixation. Clin Orthop 1991;268:21-8.

Jones JP Jr. Nontraumatic osteonecrosis of the talus. ARCO News 1993;5(2):92.

Kirkpatrick JS, Goldner JL, Goldner RD. Revision arthrodesis for tibiotalar pseudarthrosis with fibular onlay-inlay graft and internal screw fixation. Clin Orthop 1991;268:29-36.
Langevitz P, Buskila D, Stewart J, Sherrard DJ, Hercz G. Osteonecrosis in patients receiving dialysis: report of two cases and review of the literature. J Rheumatol 1990;17:402-6.

Mann RA, Van Manen JW, Wapner K, Martin J. Ankle fusion. Clin Orthop 1991;268:49-55.

Mazur JM, Schwartz E, Simon SR. Ankle arthrodesis: long-term followup with gait analysis. J Bone Joint Surg [Am] 1979;61-A:964-75.

Miskew DB, Goldflies ML. Atraumatic avascular necrosis of the talus associated with hyperuricemia. Clin Orthop 1980;148:156-9.

Mont MA, Maar DC, Urquhart MW, Lennox D, Hungerford DS. Avascular necrosis of the humeral head treated by core decompression: a retrospective review. J Bone Joint Surg [Br] 1993;75-B:7858 .

Mont MA, Hungerford DS. Non-traumatic avascular necrosis of the femoral head. J Bone Joint Surg [Am] 1995;77-A:459-74.

Mont MA, Tomek I, Hungerford DS. Core decompression for avascular necrosis of the distal femur: long-term follow-up. Clin Orthop 1997, in press.

Morris HD, Hand WL, Dunn AW. The modified Blair fusion for fractures of the talus. J Bone Joint Surg [Am] 1971;53-A:1289-97.

Scranton PE. An overview of ankle arthrodesis. Clin Orthop 1991;268:96-101.

Sowa DT, Krackow KA. Ankle fusion: a new technique of internal fixation using a compression blade plate. Foot Ankle 1989;9:232-40.

Urquhart MW, Mont MA, Michelson JD, Krackow KA, Hungerford DS. Osteonecrosis of the talus: treatment by hindfoot fusion. Foot Ankle 1996;17: in press.

Zizic TM, Hungerford DS. Avascular necrosis of bone. In: Kelley WN, Harris ED Jr, Ruddy S, Sledge CB, eds. Textbook of rheumatology. Vol.2. 2nd ed. Philadelphia, etc: WB Saunders Co, 1985:1689-1710. 